\title{
MATERIAL DIDÁTICO VISUAL NO ENSINO DE INGLÊS COMO LÍNGUA ADICIONAL PARA ESTUDANTES SURDOS ${ }^{1}$
}

\author{
Odon Bastos Dias (UFSM) \\ Ana Paula Carvalho Schmidt (UFSM)
}

\begin{abstract}
RESUMO: O debate sobre a educação de surdos vem gradativamente recebendo mais atenção na academia e na mídia. Como resultado, importantes avanços têm sido alcançados em termos de legislação sobre os direitos das pessoas surdas. Por exemplo, no campo das linguagens, a Língua Brasileira de Sinais (LIBRAS) foi reconhecida como primeira língua para propósitos de comunicação e formação de professores para o ensino de estudantes surdos (BRASIL, 2002, 2005). O ensino de Línguas Adicionais nesse contexto, especialmente a Língua Inglesa, não possui legislação específica e, assim, segue a Lei de Diretrizes e Bases da Educação que estabelece a oferta da disciplina a partir do sexto ano do ensino fundamental (BRASIL, 1996). Além da falta de diretrizes para o ensino de Língua Inglesa para estudantes surdos, identificamos também escassez de estudos sobre a produção de materiais didáticos para esse público. A partir dessas considerações, propomos material didático visual que visa, a partir de uma perspectiva sistêmico-funcional (HALLIDAY; MATTHIESSEN, 2014) desenvolver a formação de vocabulário em Inglês como Língua Adicional à LIBRAS. As atividades foram desenvolvidas em uma escola bilíngue da rede estadual do Rio Grande do Sul, de abril a dezembro de 2017. Entre os resultados observados, os estudantes passaram a utilizar o material proposto como uma fonte de referência extra para as demais atividades realizadas nas aulas de Língua Inglesa e apresentaram boa receptividade à proposta. Adicionalmente, ao longo do período, observamos que a utilização do material influenciou positivamente o desempenho dos estudantes nas tarefas avaliativas.
\end{abstract}

PALAVRAS-CHAVE: LIBRAS. Ensino de Língua Inglesa. Letramento visual.

\begin{abstract}
The debate about the education of the deaf has increasingly received attention in academia and media. As a result, important advances have been reached in terms of legislation on the rights of deaf people. For example, in the language field, the Brazilian Sign Language was recognized as the first language for the purposes of communication and teacher education for the teaching of deaf students (BRASIL, 2002, 2005). The teaching of additional languages in this context, especially the English language, is not covered by any specific legislation and, thus, it is regulated by the National Law of Directives and Bases for Education, which establishes that English shall be taught as a subject from the sixth grade of elementary school on (BRASIL, 1996). Besides the lack of directives for the teaching of English for the deaf, we also identified scarcity of studies about the production of learning materials for this target audience. From these considerations, we developed visual learning material, based on Systemic Functional theory (HALLIDAY; MATTHIESSEN, 2014) in order to help students with the formation of vocabulary in English as an additional language to the Brazilian Sign Language. The activities were developed in a special education public school in Rio Grande do Sul State from April to December 2017. The results show that the students used the material as a resource for doing other activities in the English classes and were very welcoming to our proposal. Additionally, along the period, they obtained better grades in evaluative tasks.
\end{abstract}

KEYWORDS: Brazilian Sign Language. English language teaching. Visual literacy.

\section{INTRODUÇÃO}

\footnotetext{
${ }^{1}$ Este trabalho é resultado da prática desenvolvida na disciplina de Estágio Supervisionado em Língua Inglesa IV, realizado pelo primeiro autor, sob supervisão da segunda autora.
} 
A participação da comunidade surda no sistema educacional brasileiro tem atraído a atenção da sociedade em vários momentos por meio de reivindicações dessa comunidade, como, por exemplo, a luta por um ensino adequado às necessidades dos surdos e contra a inclusão em turmas de ouvintes, o que, em 2017, foi tema da prova de redação do Exame Nacional do Ensino Médio (ENEM). A escolha desse tema para a prova ocorreu, em grande parte, por contribuições significativas da mídia, a qual preocupou-se em destacar a relevância desse debate, colocando em pauta notícias sobre o tema escolhido para a prova (MONTEIRO, 2017; MORENO, 2017; FRANCO, 2017).

A pessoa surda é, segundo definição do Decreto n. 5.626/2005, “aquela que, por ter perda auditiva, compreende e interage com o mundo por meio de experiências visuais, manifestando sua cultura principalmente pelo uso da Língua Brasileira de Sinais - LIBRAS" (BRASIL, 2005). Definida por lei (Lei n. 10.436/2002) como "meio legal de comunicação e expressão" (BRASIL, 2002), a LIBRAS é, portanto, a primeira língua para pessoas surdas no Brasil. Essa língua incorpora, ao mesmo tempo, elementos locais da região em que o estudante habita (por exemplo, referências topográficas), elementos regulares de LIBRAS e elementos remanescentes da língua de sinais francesa, da qual recebeu influência.

Diferentes aspectos da relação entre educação de surdos e linguagem têm sido investigados, como, por exemplo, o discurso inclusivo em documentos oficiais (PICONI, 2014), as práticas de letramento de surdos (LODI; BORTOLOTTI; CAVALMORETI, 2014) e o papel da LIBRAS no processo de ensino e aprendizagem de Inglês para surdos (SOUSA, 2014). Entretanto, pouca atenção parece ter sido dada à produção de material didático para o ensino de Inglês como Língua Adicional (doravante ILA) para estudantes surdos. Assim, no presente estudo, discutimos a investigação teórica e a prática docente desenvolvidas durante dois semestres de Estágio Curricular Supervisionado em Língua Inglesa em uma escola bilíngue da rede estadual do Rio Grande do Sul. Mais especificamente, descrevemos o processo de elaboração e implementação de material didático para o ensino de ILA, em uma turma de nono ano do ensino fundamental, com base nos pressupostos da Linguística Sistêmico-Funcional (HALLIDAY; MATTHIESSEN, 2014) e da Multimodalidade (CAZDEN; COPE; FAIRCLOUGH, 1996), especificamente, do Letramento Visual (KRESS; 


\section{W. Linguagens}

VAN LEEUWEN, 2006). Adicionalmente, buscamos avaliar os resultados e implicações pedagógicas da pesquisa.

Para tanto, organizamos o artigo em quatro seções, incluindo esta introdução. Na seção 2, apresentamos o referencial teórico que embasou a preparação do material didático. Na sequência, seção 3, descrevemos as etapas de elaboração e implementação do material e, por fim, na seção 4, tecemos algumas considerações e implicações do trabalho desenvolvido para o ensino de Inglês como Língua Adicional para surdos.

\section{REFERENCIAL TEÓRICO}

\subsection{CONTRIBUIÇÕES DE DIFERENTES CORRENTES DOS ESTUDOS LINGUÍSTICOS PARA A EDUCAÇÃO DE SURDOS}

Em decorrência das semelhanças e proximidades entre a terminologia criada pelo linguista Ferdinand de Saussure e a terminologia própria das línguas gestuais (LIBRAS, por exemplo), não é raro encontrar trabalhos acadêmicos estabelecendo comparações ou adotando os conceitos de Saussure sob o viés das línguas de sinais (BENASSI et al., 2016; FRYDRYCH, 2013; MACEDO, 2012). Apesar dessas analogias serem possíveis, a criação do Curso de Linguística Geral (SAUSSURE, 1995) e o advento das línguas de sinais são eventos independentes, que ocorreram em momentos diferentes na história.

Em particular, a semelhança aparece no modelo criado por Saussure para representar o signo linguístico, o qual é responsável por representar uma ideia e, para tanto, possui dois aspectos principais: o significado, ou seja, um conceito, e o significante, a representação do conceito em termos de uma imagem acústica. Por sua vez, as línguas de sinais atribuem um "significado" para um sinal específico. Assim, o sinal passa a assumir o papel do significante, o equivalente ao papel de uma palavra nas linguagens orais.

Saussure ainda estabelece a arbitrariedade do signo linguístico, definindo a relação entre um significado e um significante como sendo casual e arbitrária. Por exemplo, não há razão especial para o significante "azul” representar a cor azul, que é o significado. Um fenômeno típico das linguagens orais que evoluíram naturalmente ao longo do tempo por meio do uso, sem planejamento consciente. 


\section{W. Linguagens}

Se nas línguas orais a escolha de uma associação entre significado e significante pode ser considerada arbitrária, nas línguas de sinais tal relação eventualmente pode não ocorrer. É o caso, por exemplo, dos sinais onde o significado é percebido imediatamente com base no conhecimento compartilhado pelos interagentes, "uma imitação aproximativa e já convencionalizada de certos sinais" (FRYDRYCH, 2012, p. 291). Por outro lado, há também grande número de sinais que representam convenções arbitrárias e o seu significado dificilmente pode ser percebido por alguém que não conheça aquela convenção.

Uma peculiaridade que pode ser detectada nas línguas de sinais está na convergência de vários significantes, provenientes das linguagens orais (Português a princípio, mas a transposição para a Língua Inglesa ocorre por meio de caminho semelhante), para um único significante (sinal) em LIBRAS. Tomando como exemplo os verbos "acontecer", "existir", "haver", “ter", e "possuir", em uma situação hipotética, em que alguém deixasse um jornal sobre uma cadeira, quais desses verbos poderiam ser selecionados para descrever a cena? Todos, talvez, com um grau maior de dificuldade para acomodar os verbos "acontecer" e "possuir" na oração.

Assim, em Português: "Há (Existe ou Tem) um jornal na cadeira" e, em Inglês, "There is a newspaper on the chair", são as soluções mais simples. Em LIBRAS, a situação seria resolvida com uma sequência de apenas três sinais: "Ter"+"Jornal"+"Cadeira". Ou seja, isso representa uma convergência dos significados dos verbos "existir", "haver", "ter", e da forma "There to be", para um único significante (sinal) em LIBRAS.

Uma relação importante de se estabelecer aqui é a possibilidade de um único significado possuir mais de um significante. De volta ao exemplo da cor azul (o significado), os seus significantes podem ser expressos por: um sinal correspondente em LIBRAS, uma palavra na Língua Portuguesa (“azul”), ou uma palavra na Língua Inglesa (“blue”).

Logo, a questão de se adicionar uma outra língua ao usuário de LIBRAS também pode ser vista como o acréscimo de uma nova camada de significantes para os significados já conhecidos. Porém, essa questão pode não ser tão simples quanto parece à primeira vista, pois quando a arbitrariedade da relação entre significados e significantes se apresenta, demanda esforço para apreender a grafia de uma nova camada de significantes na Língua Adicional. Esse é o ponto em que uma proposta didática que envolva jogos de palavras, utilizando a modalidade visual e a escrita, pode contribuir para instigar os estudantes para o uso de novo 
vocabulário, ou seja, uma nova camada de significantes. Ademais, a implementação de jogos de palavras também pode ser útil para auxiliar a aprendizagem de conteúdos gramaticais do currículo escolar, por exemplo, os pronomes pessoais.

Nesse caso, é necessário explanar aos estudantes que a relação entre os pronomes pessoais na Língua Portuguesa e na Língua Inglesa é muito próxima, existindo apenas um pronome adicional em Inglês ("it"), sem correspondente direto em Português. Em LIBRAS, os pronomes pessoais possuem uma função mais próxima à referencial, desse modo, o seu uso é substituído pela ação de: 1) apontar outro indivíduo (criando uma linha tênue entre o "tu" e o "ele", pois o sinal é o mesmo nos dois casos); 2) apontar um grupo de indivíduos (criando uma linha tênue entre "vocês" e "eles"); 3) indicar um objeto ou "coisa" (o conceito de "it", portanto), ou 4) apontar para si próprio "eu", constituindo-se como sujeito do discurso. Uma exceção poderia ser o sinal para "todos", com potencial de substituir o pronome "nós" ("we"), sem necessidade de apontar um grupo inteiro de pessoas.

Émile Benveniste discute uma situação muito próxima ao problema exposto no parágrafo anterior, quando afirma que:

\footnotetext{
O essencial é, portanto, a relação entre o indicador (de pessoa, de tempo, de lugar, de objeto mostrado, etc.) e a presente instância de discurso. De fato, desde que não se visa mais, pela própria expressão, essa relação do indicador à instância única que o manifesta, a língua recorre a uma série de termos distintos que correspondem um a um aos primeiros, e que se referem não mais à instância de discurso, mas aos objetos "reais", aos tempos e lugares "históricos". Daí as correlações como eu:ele - aqui:lá - agora:então - hoje:no mesmo dia - ontem: na véspera - na próxima semana: na semana seguinte - há três dias:três dias antes, etc. A própria língua revela a diferença profunda entre estes dois planos (BENVENISTE, 1995, p. 280).
}

Assim, é possível estabelecer uma correlação semelhante entre nós:todos. Por outro lado, o indicador de pronome pessoal, em LIBRAS, representado pelo ato de apontar, parece não estabelecer a mesma correlação que permite diferenciar a segunda pessoa do singular da terceira. Ou seja, apontando para o "outro", como estabelecer a correlação que diferencia o "outro" de "tu", e o "outro" de "ele"? Há que se considerar que apontar "tu" ou "ele" é um ato idêntico nas duas situações. Benveniste comenta que "há enunciados de discurso, que a despeito de sua natureza individual, escapam a condição de pessoa, isto é, remetem não a eles mesmos, mas a uma situação "objetiva". É o domínio daquilo a que chamamos a "terceira pessoa"”'(BENVENISTE, 1995, p. 282). 


\title{
Linguagens
}

Em tais circunstâncias, as diferenças entre o "outro", "tu", "você" e "ele" (ou "ela") é meramente formal:

\begin{abstract}
O fato de que a "terceira pessoa" é realmente uma "não-pessoa" certos idiomas o mostram literalmente. (...) É principalmente o caso das línguas modernas de pronome obrigatório nas quais ele parece, continuando eu e tu, membro de um paradigma de três termos; ou da flexão indo-européia de presente, com -mi, -si, -ti. $\mathrm{Na}$ verdade, a simetria é somente formal. O que é preciso considerar como distintivo da "terceira pessoa" é a propriedade: $1^{\circ}$. de se combinar com qualquer referência de objeto; $2^{\circ}$. de não ser jamais reflexiva da instância de discurso; $3^{\circ}$. de comportar um número às vezes bastante grande de variantes pronominais ou demonstrativas; $4^{\circ}$. de não ser compatível com o paradigma de termos referenciais como aqui, agora, etc. (BENVENISTE, 1995, p. 283).
\end{abstract}

Embora os trabalhos de Saussure e Benveniste não houvessem, especificamente, sido escritos com enfoque na língua de sinais, apontamos acima relações plausíveis que podem ser estabelecidas entre princípios das abordagens estruturalista e enunciativa da linguagem e a educação de surdos. Nosso trabalho de elaboração de material didático considera essas relações; entretanto, situa-se em uma perspectiva de linguagem em que a relação entre esses grupos distintos de palavras seja apresentada como um sistema de escolhas (HALLIDAY; MATTHIESSEN, 2014) e não um sistema de regras puramente gramatical. Essa perspectiva permite ainda destacar outro importante aspecto: as possíveis traduções entre os diferentes sistemas linguísticos envolvidos (Inglês - Português - LIBRAS), conforme sugerido por Halliday:

\begin{abstract}
Grande parte das pesquisas em línguas de sinais tem enfatizado o estudo de características no estrato da léxico-gramática, e especialmente, no contexto de comparação às línguas orais. Mas as escolhas de significados disponíveis ao sinalizador - o potencial do potencial de significação, por assim dizer - são consideravelmente distintas de vários modos e, se pudessem ser representadas na forma de redes semânticas, poderíamos aprender muito mais sobre os recursos semióticos subjacentes à língua humana (HALLIDAY, 2013, p. 35)².
\end{abstract}

Exemplos do potencial de significação disponíveis ao sinalizador foram mencionados anteriormente, com os comentários sobre as correlações entre indicadores de pessoa, por

\footnotetext{
${ }^{2} \mathrm{Cf}$. o trecho original: "Most research into Sign has foregrounded the study of features at the lexicogrammatical stratum, and that especially in the context of comparison with spoken languages. But the choices in meaning that are available to a signer - the meaning potential potential, so to speak - are in many ways significantly different, and if these can be represented in the form of semantic networks we might learn quite a lot more about the semiotic resources latent in human language".
} 


\section{Linguagens}

exemplo a relação "nós:todos". Tais correlações revelam as particularidades das traduções entre as línguas orais e as línguas de sinais. Admitindo-se a língua como um sistema de escolhas, é necessário que correlações desse tipo (as opções existentes nos sistemas) sejam explicitadas. Halliday deixava isso muito claro em sua teoria:

O falante de uma língua, como uma pessoa que se envolve em qualquer tipo de comportamento culturalmente determinado, pode ser visto como realizando, simultânea e sucessivamente, várias escolhas distintas. Em qualquer dado momento, no ambiente das seleções feitas para aquele instante, uma certa variedade de escolhas adicionais está disponível. É o sistema que formaliza a noção de escolha na linguagem (FONTAINE, 2013, p. 99, com base em HALLIDAY, 1976) ${ }^{3}$.

Os pressupostos teóricos da Linguística Sistêmico-Funcional, além da contribuição para descrição e análise linguística, têm embasado estudos no campo da educação, nos diversos níveis de ensino. Neste trabalho, nos interessam as pesquisas conduzidas com foco na educação básica, especialmente a Pedagogia de Multiletramentos, sobre a qual discutiremos na próxima subseção.

\subsection{PEDAGOGIA DE MULTILETRAMENTOS}

A Pedagogia de Multiletramentos resultou da reunião de um pequeno grupo de pesquisadores, de diferentes nacionalidades, na cidade de Nova Londres, Estados Unidos, em 1994. O grupo reuniu-se, principalmente, para discutir a educação em uma sociedade culturalmente diversa, na qual uma multiplicidade de modos de significar desempenha um papel tão importante quanto a linguagem verbal escrita (CAZDEN et al., 1996). Com essa constatação a respeito da sociedade, os pesquisadores elaboraram uma teoria que apresenta seis elementos de configuração no processo de construção de significado: a) linguístico, b) visual, c) de áudio, d) gestual, e) espacial e f) multimodal (NEW LONDON GROUP, 1996, p. 21), dentre os quais nos interessa o significado visual.

\footnotetext{
${ }^{3}$ Cf. o trecho original: "The speaker of a language, like a person engaging in any kind of culturally determined behaviour, can be regarded as carrying out, simultaneously and successively, a number of distinct choices. At any given moment, in the environment of the selections made up to that time, a certain range of further choices is available. It is the system that formalizes the notion of choice in language".
} 
Uma proposta de material didático que toma por base a construção de significados visuais pode oferecer aos estudantes surdos: 1) estímulo na luta contra a implementação de uma abordagem oralista; 2) a perspectiva de que eles talvez não precisem aprender "uma língua oral para se tornarem letrados e, na verdade, multiletrados ${ }^{4}$ " (NEWFIELD et al., 2001, p. 135). Nesse sentido, concordamos com Cazden et al. (1996, p. 72) quando afirmam que "o papel da pedagogia é desenvolver uma epistemologia do pluralismo que forneça acesso sem que as pessoas tenham que apagar ou deixar para trás diferentes subjetividades 5 ". Portanto, as particularidades linguísticas e extralinguísticas das interações entre surdos devem ser consideradas no desenvolvimento de materiais para o ensino de Línguas Adicionais.

Além da importância de enfocar a identidade e as particularidades de nossos alunos, nós, professores, temos ciência "do crescente papel da comunicação visual nos materiais didáticos de diversos tipos" e temos nos questionado sobre as formas mais eficazes de uso de imagens para a aprendizagem (KRESS; VAN LEEUWEN, 2006, p. 14). Um exemplo de proposta didática com o uso de recursos visuais para surdos é o trabalho desenvolvido por Vieira (2009) para o ensino de leitura em Língua Portuguesa por meio de quadrinhos e tirinhas. Em nossa investigação, definimos o gênero discursivo multimodal ilustração, em combinação com a modalidade escrita, para a composição de cartelas como proposta de material didático para o ensino de ILA em uma turma de estudantes surdos.

$\mathrm{Na}$ próxima seção, apresentamos essa proposta e relatamos como ocorreu sua implementação, após a descrição do contexto de ensino.

\section{ELABORAÇÃO E IMPLEMENTAÇÃO DO MATERIAL DIDÁTICO}

As atividades ocorreram no período de abril a dezembro de 2017, em uma escola bilíngue da rede estadual do Rio Grande do Sul. A escola possui 78 estudantes matriculados e conta com um corpo docente de 28 professores. Os professores das séries iniciais possuem formação em Educação Especial e os professores do ensino fundamental e médio, por sua vez, possuem formação na área das disciplinas que ministram e especialização em educação de

\footnotetext{
${ }^{4}$ Cf. o trecho original: "an oral language in order to become literate and, indeed, multiliterate".

${ }^{5}$ Cf. o trecho original: "The role of pedagogy is to develop an epistemology of pluralism that provides access without people having to erase or leave behind different subjectivities".
} 


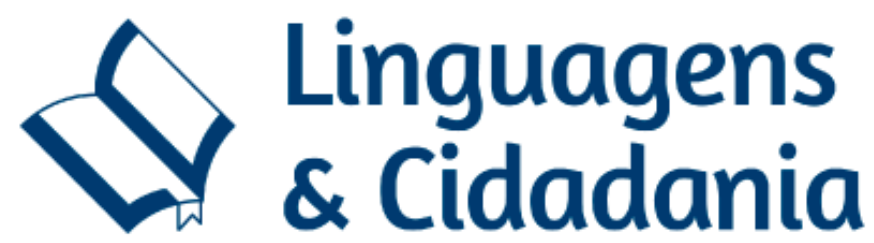

surdos. Sete estudantes de uma turma de nono ano do ensino fundamental, do período matutino, participaram da pesquisa.

Inicialmente, para embasar a elaboração do material, recorremos a fontes documentais como os Parâmetros Curriculares Nacionais (PCNs) e a proposta curricular da escola para que os conteúdos previstos para a disciplina de Língua Inglesa fossem contemplados em nosso planejamento. O material é composto por 32 cartelas que foram apresentadas à turma de acordo com a extensão de cada palavra, das curtas às mais longas. Cada cartela contém, de um lado, uma palavra em Inglês (modalidade escrita) e, do outro, uma ilustração correspondente a essa palavra (modalidade visual). A Figura 1 apresenta um exemplo utilizado em aula:

Figura 1 - Cartela Cup

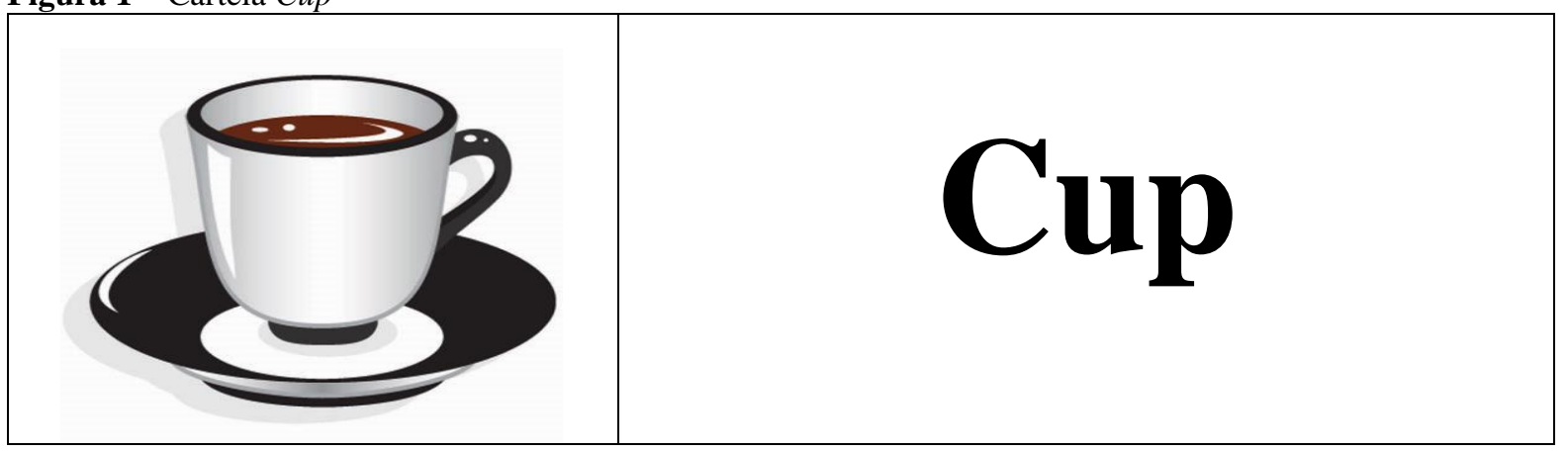

A Figura 2 apresenta a próxima palavra sugerida:

Figura 2 - Cartela Cake

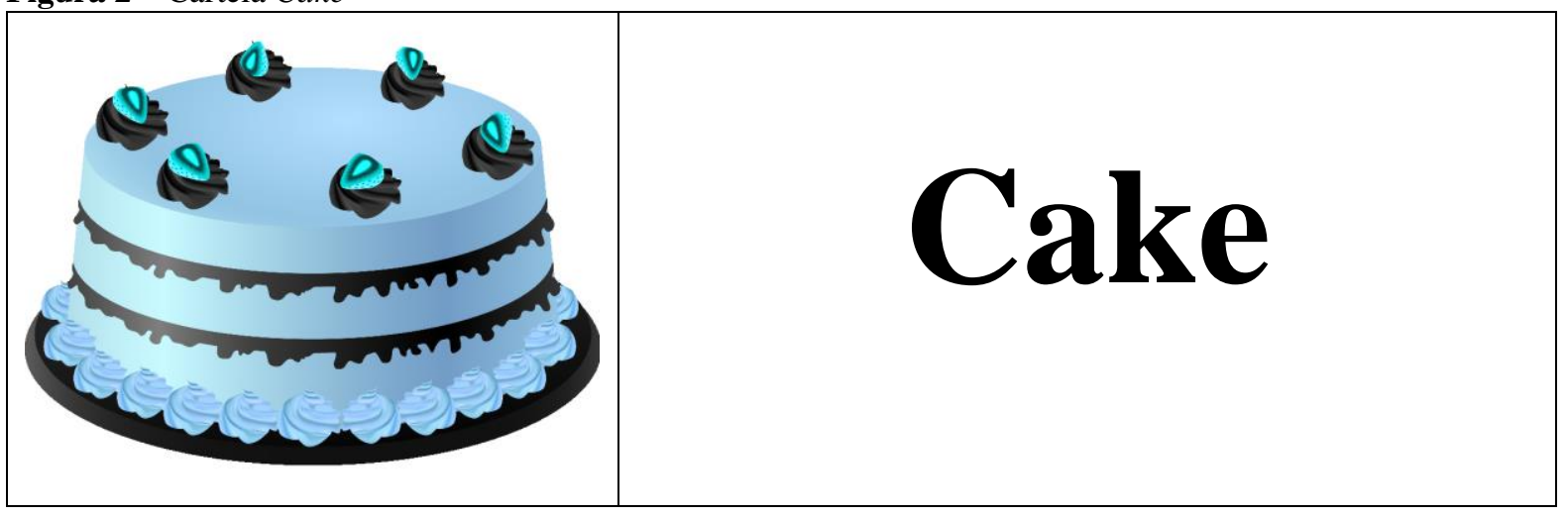

A escolha de palavras que fazem parte de um mesmo campo lexical não é uma ação aleatória: privilegia aquelas que favorecem um processo de composição, resultando na formação de uma terceira palavra derivada das anteriores. A Figura 3 demonstra essa 


\section{Ringuagens}

possibilidade, como uma forma de ampliar vocabulário, sem recorrer à memorização, ao combinar palavras apresentadas anteriormente aos estudantes.

Figura 3 - Cartela Cupcake

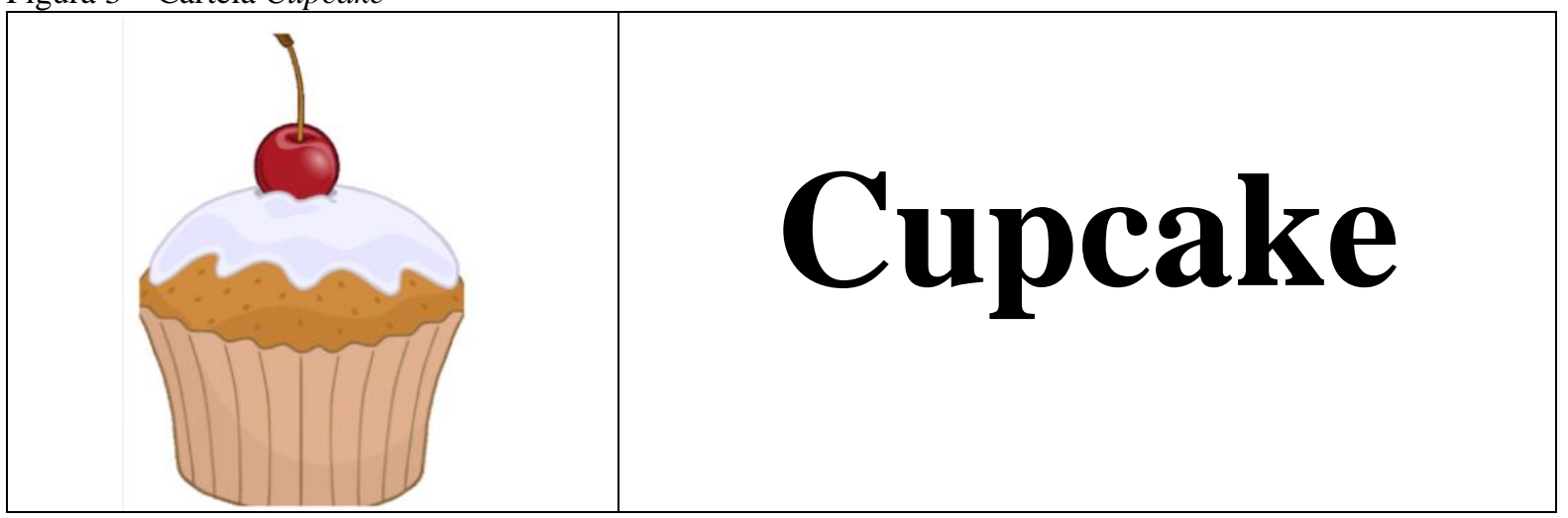

Toda vez que uma cartela é exibida, pede-se aos estudantes para "soletrar" o nome do objeto representado na ilustração com o alfabeto datilológico ou manual. Então, finalmente é exibido o verso da cartela, onde está o nome do objeto.

Para transformar a atividade em um jogo, são convidados dois voluntários e uma cartela é distribuída a cada um deles. O voluntário deve perguntar ao colega o nome do objeto sugerido na ilustração que está exibindo. O colega deve soletrar (com o alfabeto manual) a resposta, de forma correta, para obter um acerto. Se o colega errar, o outro soletrará o nome do objeto da ilustração, conforme está impresso no verso da cartela.

É importante ajustar o número de lexemas à quantidade de estudantes da turma para que, após as cartelas serem distribuídas, todos possam participar da atividade. Os demais estudantes, aos pares, devem repetir o procedimento dos voluntários e trocar cartelas com os outros pares, aleatoriamente. O processo é encerrado, uma vez que cada estudante tenha visto todas as cartelas ao menos uma vez. Esse trabalho em pares parte de uma visão de aprendizagem como "co-participação social (isto é, participação com alguém em contextos de ação) entre pares na resolução de uma tarefa em que a participação do aluno é periférica, inicialmente, até passar a ser plena com o desenvolvimento da aprendizagem" (BRASIL, 1998).

$\mathrm{Na}$ parte final da aula, sempre que possível, a última atividade tem o objetivo de avaliar o processo de aprendizagem de vocabulário. Todos os estudantes recebem uma folha em branco, na qual devem escrever o nome de cada objeto, que é apresentado novamente pelo 


\section{W. Linguagens}

professor, conforme lembrarem-se da grafia em Língua Inglesa. Os resultados são avaliados a partir do número de acertos individuais dos estudantes e da qualidade das respostas.

Com vistas a incluir um dos temas transversais sugeridos pelos PCNs, a pluralidade cultural, escolhemos a temática festa do chá (tea party) para contextualizar os conteúdos léxico-gramaticais que seriam apresentados aos estudantes. A escolha da temática é um convite à reflexão sobre outras formas de viver e interagir no mundo e, ao mesmo tempo, ao reconhecimento e valorização da "pluralidade do patrimônio sociocultural brasileiro [...], posicionando-se contra qualquer discriminação baseada em diferenças culturais, de classe social, de crenças, de sexo, de etnia ou outras características individuais e sociais" (BRASIL, 1997).

Dessa forma, os estudantes entram em contato com práticas sociais de outros países, ao mesmo tempo que são convidados a refletir sobre as práticas sociais do contexto onde vivem. Inicialmente, na primeira coleção de cartelas, buscávamos explorar o conhecimento prévio dos estudantes sobre o conteúdo proposto pelo currículo da escola relacionado às "cores". A segunda coleção de cartelas consistiu na apresentação dos pronomes pessoais. Conforme discutido anteriormente, a simples correlação entre os significantes (por exemplo, "ele"/"he") pode ser pouco esclarecedora dos significados desses pronomes. Logo, o modo de representar figurativamente cada pronome em uma ilustração na cartela deve considerar antes a situação social onde tal pronome ocorre (por exemplo, duas pessoas conversando e apontando para uma outra, a terceira pessoa do singular). Por fim, a terceira coleção de cartelas enfocou ações e objetos que fazem parte de uma situação de encontro de crianças para uma festa do chá.

Nessa proposta buscamos conciliar os conteúdos recomendados pelo currículo escolar - cores e pronomes pessoais - com lexemas pertencentes ao campo semântico do chá da tarde. Para a organização da sequência de apresentação dos lexemas, recorremos aos conceitos de hiperonímia e hiponímia, por meio das quais uma palavra específica (hipônimo), por exemplo xícara (cup), relaciona-se a um termo geral (hiperônimo), como louça (dishware).

Na próxima seção, com base na fundamentação teórica apresentada anteriormente, refletimos sobre a aprendizagem dos estudantes e nossa prática e formação profissional no processo de elaboração do material didático para uma comunidade de estudantes surdos. 


\section{W. Linguagens}

\section{CONSIDERAÇÕES FINAIS}

Neste trabalho, encontramos suporte na teoria Linguística Sistêmico-Funcional, em especial na Pedagogia dos Multiletramentos para embasar uma proposta de material didático para o ensino de ILA para surdos. A pesquisa, a adaptabilidade e a flexibilização no processo de produção do material revelaram-se muito importantes pois, como um dos resultados, observamos crescente dedicação dos estudantes às atividades propostas. Um indicador dessa dedicação foi a utilização das atividades e cartelas de aulas anteriores como material de consulta a cada aula. Adicionalmente, os estudantes demonstraram interesse ampliado para buscar informações necessárias à solução dos exercícios e uma boa receptividade à proposta apresentada. Além desses resultados, o bom desempenho na formação do vocabulário foi muito importante para a etapa seguinte: a construção de orações em Língua Inglesa. Tal proposta foi realizada com base em ilustrações que formam uma rede semântica de possibilidades disponíveis para a construção de representações de participantes, relacionandoos a processos materiais, ou seja, ações que ocorrem em determinadas circunstâncias. Os resultados práticos em aula demonstraram a importância da criação e utilização de redes semânticas na apresentação de possibilidades de tradução entre os diferentes sistemas linguísticos.

O processo de aprendizagem do professor em formação (primeiro autor) também pode ser visto como um reflexo diante da receptividade e aprendizagem dos estudantes. Em particular, a elaboração do próprio material didático, mesmo com a demanda de tempo em pesquisa e preparação, tornou-se um fator primordial na formação profissional do professor pré-serviço. Por fim, com este relato de experiência, esperamos contribuir para o debate sobre o ensino de Línguas Adicionais para surdos e, também, que nosso material possa ser revisto, adaptado e ampliado para outros contextos de ensino.

\section{REFERÊNCIAS}

BENASSI, C. A. et al. Diacronia e sincronia: questões estruturais e de sentido na LIBRAS. Revista Diálogos, v. 4, n. 2, p. 12-31, 2016. 


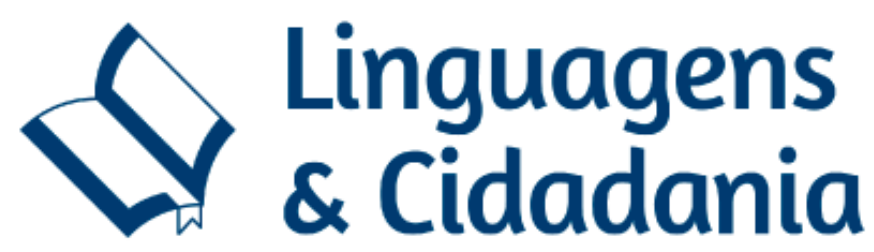

BENVENISTE, E. Problemas de linguística geral I. Tradução Maria da Glória Novak e Maria Luisa Neri. 4. ed. Campinas, SP: Pontes, 1995.

BRASIL. Lei de Diretrizes e Bases da Educação Nacional. Lei número 9394, 20 de dezembro de 1996. Disponível em: 〈 http://www.planalto.gov.br/Ccivil_03/leis/L9394.htm>. Acesso em: 13 fev. 2018.

Parâmetros curriculares nacionais: terceiro e quarto ciclos do ensino fundamental: língua estrangeira. Secretaria de Educação Fundamental. Brasília: MEC/SEF, 1998.

Lei $\mathrm{n}^{\circ}$ 10.436, de 24 de abril de 2002. Dispõe sobre a Língua Brasileira de Sinais e dá outras providências. Diário Oficial da União, Brasília, 25 abr. 2002. Disponível em: <http://www.planalto.gov.br/ccivil_03/leis/2002/110436.htm>. Acesso em: 23 jan. 2018.

Decreto-Lei no 5.626, de 22 de dezembro de 2005. Regulamenta a Lei no 10.436, de 24 de abril de 2002, que dispõe sobre a Língua Brasileira de Sinais - LIBRAS, e o art. 18 da Lei n. 10.098, de 19 de dez. 2000. Diário Oficial da União, Brasília, 23 dez. 2005. Disponível em: <http://www.planalto.gov.br/ccivil_03/_Ato2004-2006/2005/Decreto/D5626.htm>. Acesso em: 23 jan. 2018.

CAZDEN, C. et al. A pedagogy of multiliteracies: designing social futures. Harvard Education Review, v. 66, n. 1, 1996, p. 60-92.

FONTAINE, L. Semantic options and complex functions. In: FONTAINE, L.; BARTLETT, T.; O'GRADY, G. (Ed.). Systemic Functional Linguistics: exploring choice. Nova Iorque: Cambridge University Press, 2013. p. 95-114.

FRANCO, L. Tema de redação do Enem surpreende e emociona alunos de escola de surdos. Jornal Folha de São Paulo on-line. Disponível em: < http://www1.folha.uol.com.br/educacao/2017/11/1933299-tema-de-redacao-do-enemsurpreende-e-emociona-alunos-de-escola-de-surdos.shtml>. Acesso em: 23 jan. 2018.

FRYDRYCH, L. A. K. O estatuto linguístico das línguas de sinais: a Libras sob a ótica saussuriana. 2013. 92f. Dissertação (Mestrado em Letras) - Universidade Federal do Rio Grande do Sul. Porto Alegre, 2013.

Rediscutindo as noções de arbitrariedade e iconicidade: implicações para o estatuto linguístico da Língua de Sinais. ReVEL, v. 10, n. 19, 2012.

HALLIDAY, M. A. K; MATTHIESSEN, C. M. I. C. Halliday's introduction to functional grammar. 4.ed. Nova Iorque: Routledge, 2014.

HALLIDAY, M. A. K. Meaning as choice. In: FONTAINE, L. et al. (Ed.). Systemic Functional Linguistics: exploring choice. Nova Iorque: Cambridge University Press, 2013. p. 15-36. 


\section{W. Linguagens}

KRESS, G.; VAN LEEUWEN, T. Reading images: the grammar of visual design. Londres: Routledge, 2006.

LODI; A. C. B. et al. Letramentos de surdos: práticas sociais de linguagem entre duas línguas/ culturas. Bakhtiniana, v. 9, n. 2, ago./dez. 2014, p. 131-49. Disponível em:

<http://www.scielo.br/pdf/bak/v9n2/a09v9n2.pdf $>$. Acesso em: 24 jan. 2018.

MACEDO, M. A. de. A literatura infantil para crianças surdas. 2012. 40f. Monografia (Graduação em Letras) - Universidade Católica de Brasília. Brasília, 2012.

MONTEIRO, C. ENEM: quais as dificuldades que os surdos enfrentam na Educação brasileira? Nova Escola on-line. Disponível em:

$<$ https://novaescola.org.br/conteudo/7094/enem-quais-as-dificuldades-que-os-surdos-

enfrentam-na-educacao-brasileira $>$. Acesso em: 23 jan. 2018.

MORENO, A. C. Tema da redação do ENEM 2017 fala sobre a educação de surdos no Brasil. Portal de notícias da Globo G1. Disponível em:

$<$ https://g1.globo.com/educacao/enem/2017/noticia/tema-da-redacao-do-enem-2017-falasobre-a-educacao-de-surdos-no-brasil.ghtml>. Acesso em: 23 jan. 2018.

NEWFIELD, D. et al. Exploding the monolith: Multiliteracies in South Africa. In:

KALANTZIS, M.; COPE, B. Transformations in language and learning: perspectives on multiliteracies. Austrália: Common Ground Publishing, 2001.

NEW LONDON GROUP. A Pedagogy of multiliteracies: designing social futures. Harvard Educational Review, v. 66, 1996, p. 60-92.

PICONI, L. B. Teaching languages to deaf students in Brazil at the intersection of discourses.

Revista Brasileira de Linguística Aplicada, v. 14, n. 4, dez. 2014, p. 881-904. Disponível em: <http://www.scielo.br/scielo.php?script=sci_arttext\&pid=S1984-

63982014000400006\&lng=en\&nrm=iso $>$. Acesso em: 23 jan. 2018.

SAUSSURE, F. Curso de Linguística Geral. 26.ed. Tradução de Antônio Chelini, José Paulo Paes e Izidoro Blikstein. São Paulo: Cultrix: 1995.

SOUSA, A. N. de. Reflexões sobre as práticas de ensino de uma professora de Inglês para surdos: a língua de sinais brasileira como mediadora do processo de ensino-aprendizagem.

Revista Brasileira de Linguística Aplicada, v. 14, n. 4, dez. 2014, p. 1015-1044. Disponível em: <http://www.scielo.br/scielo.php?script=sci_arttext\&pid=S1984-

63982014000400011\&lng=en\&nrm=iso>. Acesso em: 24 jan. 2018.

VIEIRA, P. A. O uso dos gêneros quadrinhos e tirinhas no ensino de leitura em

Português como segunda língua: por uma abordagem bilíngue para os surdos. 2009. $216 f$. Dissertação (Mestrado Acadêmico em Linguística Aplicada) - Universidade Estadual do Ceará. Fortaleza, 2009. 